\title{
Analysis of High Temperature Steam Oxidation of Superheater Steels Used in Coal Fired Boilers
}

\author{
T. Dudziak ${ }^{1} \cdot$ M. Lukaszewicz ${ }^{2}$ N. Simms ${ }^{3}$ • \\ J. Nicholls ${ }^{3}$
}

Received: 14 July 2015/Revised: 30 September 2015/Published online: 30 October 2015

(C) The Author(s) 2015. This article is published with open access at Springerlink.com

\begin{abstract}
The present work compares the behaviour of four steels: (T23, T92, T347HFG, Super304H) in the temperature range $600-750{ }^{\circ} \mathrm{C}$. This study focuses on the analysis of the oxidation kinetics in terms of mass change, metal loss and thickness change of the selected materials. In order to understand the differences in oxidation rates between the selected steels, the impact of chromium and the alloying elements were considered in this work. The obtained results show that the impact of alloying elements differs with exposure conditions and importance of the synergy effect.
\end{abstract}

Keywords Steam oxidation · Ferritic steels · Austenitic steels $\cdot$ High temperature EDX $\cdot$ SEM $\cdot$ Coal power plant

Finally, the work was performed in Cranfield University, School of Apllied Science, Centre for Energy and Resource Technology, MK43 0AL Cranfield, United Kingdom.

T. Dudziak

tomasz.dudziak@iod.krakow.pl

M. Łukaszewicz

Mikolaj.Lukaszewicz@Exova.com

N. Simms

N.J.Simms@cranfield.ac.uk

J. Nicholls

j.r.nicholls@cranfield.ac.uk

1 Foundry Research Institute, Centre for High Temperature Studies, Zakopiańska 73, 30-418 Kraków, Poland

2 Exova (UK) Ltd, 12 High March, Daventry, Northamptonshire NN11 4HB, UK

3 School of Applied Science, Cranfield University, Cranfield, Bedfordshire MK43 0AL, UK 


\section{Introduction}

Raising environmental awareness is driving the global economy towards the reduction of $\mathrm{CO}_{2}$ emissions and fuel consumption [1]. The energy sector is contributing to these goals by increasing power generation efficiency; for conventional systems this is a strong function of temperature and pressure of steam entering the steam turbine [2-4]. Higher operational temperatures can cause serious problems for boiler components due to their effects in reducing component lifetime. Steam oxidation of high temperature resistant steels has an important impact on the power plant lifetime and efficiency. Higher operational temperatures significantly accelerate oxidation processes, which in turn lead to the development of thick, non-protective oxides especially in low alloyed steels. The important concern resulting from fast oxide growth is reduction of heat transfer and the pipe ability to withstand the high steam pressures due to the metal loss [5]. Material strength at high temperature is the main concern, the creep resistance of steels under harsh conditions (temperature, stress) limits the maximum application temperature [6]. Especially, the steels with relatively low $\mathrm{Cr}$ addition like T23 or T92 exposed at high temperatures $\left(590-620^{\circ} \mathrm{C}\right)$. Nevertheless, creep strength of those steels is considerably higher than that for T22 and T91 respectively due to addition of $\mathrm{Nb}, \mathrm{V}$ and substitution of Mo for W [7].

Finally, the stresses generated during the oxide growth and high temperature exposure changes the scale morphology and leads to exfoliation and finally materials failures [8]. Therefore, understanding the steam oxidation processes and factors influencing them is crucial for improvement of power plant efficiency [9]. Currently research for the power plant components concentrates on understanding the steam oxidation behaviour of the materials which can withstand steam temperature up to 650,700 and $760{ }^{\circ} \mathrm{C}$ for European COST-522, European Thermie and US Department of Energy's Vision 21 programmes respectively, therefore those materials have to exhibit good creep rapture strength and oxidation resistance [1]. Three groups of the materials are considered as the prospective candidates for the ultra supercritical (USC) boiler tubing [8-10]:

- Ferritic steels;

- Austenitic steels;

- Nickel -based steels.

The materials are characterised by different conductivity, temperature, steam oxidation behaviour, and creep resistance [11-14]. These properties have significant impact on their performance in steam conditions [9].

The last decade has brought the extensive research and development of the highstrength ferritic steels [15], which have good mechanical and physical properties and significantly reduce cost of the power plant construction [2]. The two ferritic steels which are successfully applied for boilers components in existing power plants are T23 (7CrWMoVNb9-6) and T92 (X10CrWMoVNb9-2), therefore steam oxidation of these two steels is analysed and compared. Steam oxidation of T23 and 
T92 steels at low temperature is well documented in the literature therefore particular research aims to investigate their performance under significantly higher conditions.

Austenitic steels are commonly used for the final superheater $(\mathrm{SH})$ tubing due to their good oxidation resistance [16]. In particular research two types of $18 \mathrm{wt} \% \mathrm{Cr}$ austenitic steels are tested-T347HFG (X6CrNiNb18-10) and Super 304H (X5CrNi18-10), both steels are already used in the final stages of the $\mathrm{SH}$ in coalfired plants $[17,18]$.

This article aims to investigate and compare high temperature steam oxidation behaviour of ferritic and austenitic steels as well as study the differences within these two groups. Furthermore the selection of the tested conditions allows investigation and understanding of the oxidation behaviour of ferritic steels above their standard operational conditions. The main emphasis is placed on the analysis of the possibilities for extending the use of the $9 \% \mathrm{Cr}$ steels above $600{ }^{\circ} \mathrm{C}$ and comparison of its performance with T23 and more temperature resistant T347HFG and Super $304 \mathrm{H}$.

\section{Experimental Procedures}

In this work T23, T92 ferritic, ferritic/martensitic steels and austenitic: T347HFG, Super $304 \mathrm{H}$ materials were used. The samples were machined $(15 \mathrm{~mm} \times 15 \mathrm{~mm})$, with thicknesses differing with the steel type as following: 5, 6, 4 and $8(\mathrm{~mm})$ for T23, T92, T347HFG and Super 304H respectively. The shape of the samples used in the study is presented in Fig. 1. The chemical composition (wt\%) of the studied steels is presented in Table 1. Prior to the exposure the samples were ground to a UK 600 grit surface finish and cleaned in an ultrasonic bath firstly in volasil and secondly in isopropanol at $30{ }^{\circ} \mathrm{C}$ for $10 \mathrm{~min}$ in order to remove grease and other impurities. Steam oxidation tests at elevated temperatures were carried out in a horizontal furnace, using an alumina lined steel reaction vessel. The specimens were placed inside the tube, additionally due to expected spallation of the scale formed,
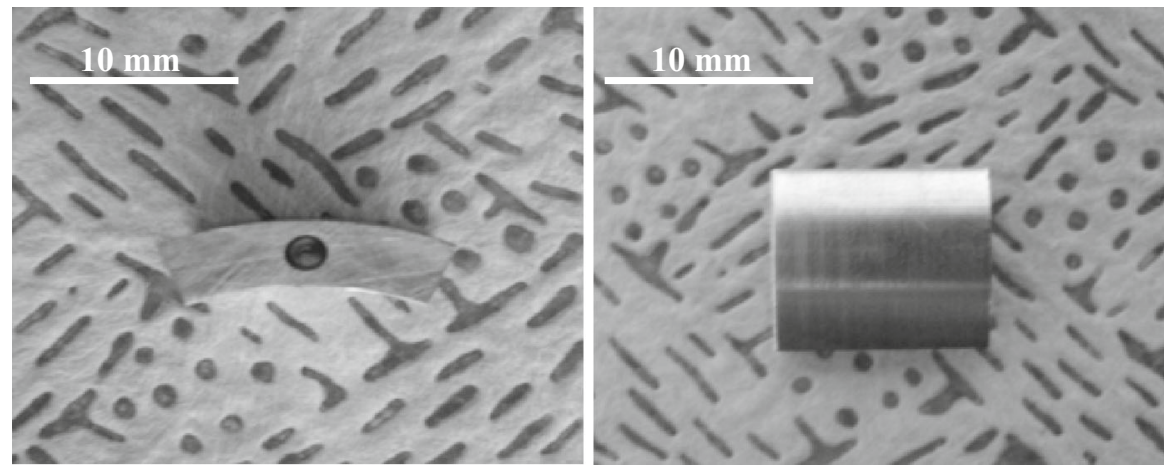

Fig. 1 Specimen before exposure 
Table 1 Chemical composition (wt\%) of the tested steels obtain with EDX

\begin{tabular}{llllllllll}
\hline Steel grade & $\mathrm{C}$ & $\mathrm{Fe}$ & $\mathrm{Cr}$ & $\mathrm{Ni}$ & $\mathrm{Mo}$ & $\mathrm{W}$ & $\mathrm{Si}$ & $\mathrm{Mn}$ & $\mathrm{N}$ \\
\hline T23 & 0.06 & $\mathrm{Bal}$ & 2.25 & - & 1 & 1.5 & 0.2 & 0.45 & - \\
T92 & 0.13 & $\mathrm{Bal}$ & 9 & 0.4 & 1 & 1.87 & 2 & 0.6 & - \\
T347HFG & 0.1 & $\mathrm{Bal}$ & 18 & 9 & - & - & 0.6 & 1.6 & - \\
Super304H & 0.1 & $\mathrm{Bal}$ & 18 & 10 & - & - & 0.2 & 0.8 & 0.1 \\
\hline
\end{tabular}

were put into crucibles. Moreover; use of crucibles ensures the proper mass change readings, at relatively low temperature in particular, when the austenitic steels indicated low mass gain.

Steam oxidation test facility is shown in Fig. 2 steam is generated by pumping water from a reservoir into the furnace. Then it passes over the crucibles with samples and flows into a condenser before the water returns to the reservoir, the water is double de-ionised. Before starting the test, the system is sealed and thoroughly purged using 'oxygen free nitrogen' (OFN). This purge continues through the water reservoir throughout the samples exposure period to minimise the level of oxygen in the system. Specimens mass change was monitor discontinuously, after each $250 \mathrm{~h}$, the corroded samples were weighted using the analytical scale. In this regard the furnace was cooled down to room temperature in high purity nitrogen atmosphere, when temperature was reached specimens were unloaded and weighted. Afterwards the crucibles were placed back in the chamber and the furnace was heated up to the exposure temperature firstly in nitrogen to $100{ }^{\circ} \mathrm{C}$, then up to temperature of interest in $100 \%$ steam. To ensure the isothermal character of the tests conducted, during the whole $1000 \mathrm{~h}$ temperature inside the alumina tube have

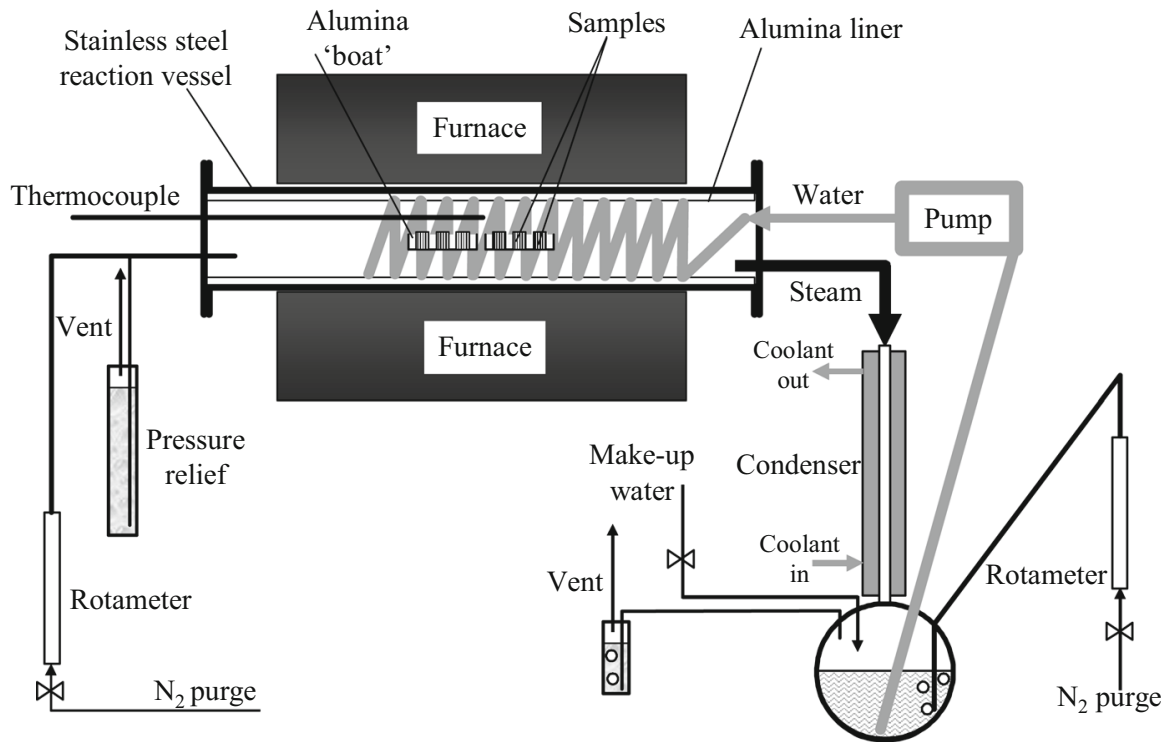

Fig. 2 Schematic diagram of steam oxidation test facility 
been monitored, using the thermocouple connected to the computer using PICO TC08 thermocouple data logger. The installed software allowed obtaining temperature readings in every $5 \mathrm{~s}$ for the test duration.

Metal loss was studied by comparison of the dimensions of the samples before the exposures, obtained with the digital micrometre and the data after exposure, acquired with the image analyser. The technique uses a digital image analyser. By comparing the sample dimensions before and after exposure, the apparent change in metal and the change in sound metal (change in metal+internal damage) can be calculated. These data sets can then be re-ordered (from greatest to least metal loss) and corrected for calibration differences (using data from reference samples). The processed data can then be plotted as a change in metal versus cumulative probability; effectively, this type of plot indicates the probability (e.g. $4 \%$ ) of a certain degree of damage being observed. The image analyser is connected with an optical microscope. For the data acquisition the software, Axio-vision was used.

Figure 3 shows a schematic on the $x-y$ stage for the analysis. The sample is placed on the motorised $x-y$ stage (cross-sectioned, grinded and polished). An important step is to ensure that the long side of specimen is parallel to the x-motion of the stage. After this process, the main cross-section locations (top, bottom, right and left) on the sample are fixed. The machine calculated the $\mathrm{x}-\mathrm{y}$ co-ordinates around the sample. It was found, that for the best calculating results, $\sim 55$ or more points around the sample is required. The images are recorded during measurement, the software automatically made 9 individual pictures of each point. These images later are stitched together and the obvious metal losses in each of these images were pinpointed. Figure 4 demonstrates the function of image analyser (e.g. at point B the $\mathrm{x}$-value $=\mathrm{b} 2$ and the $\mathrm{y}$ value $=\mathrm{a} 2$ ). More detailed description of metal loss analyses can be found via literature [19-22].

The instrument was successfully used to obtain metal loss of the ferritic and austenitic materials after fireside corrosion tests at high temperatures [23, 24]. The

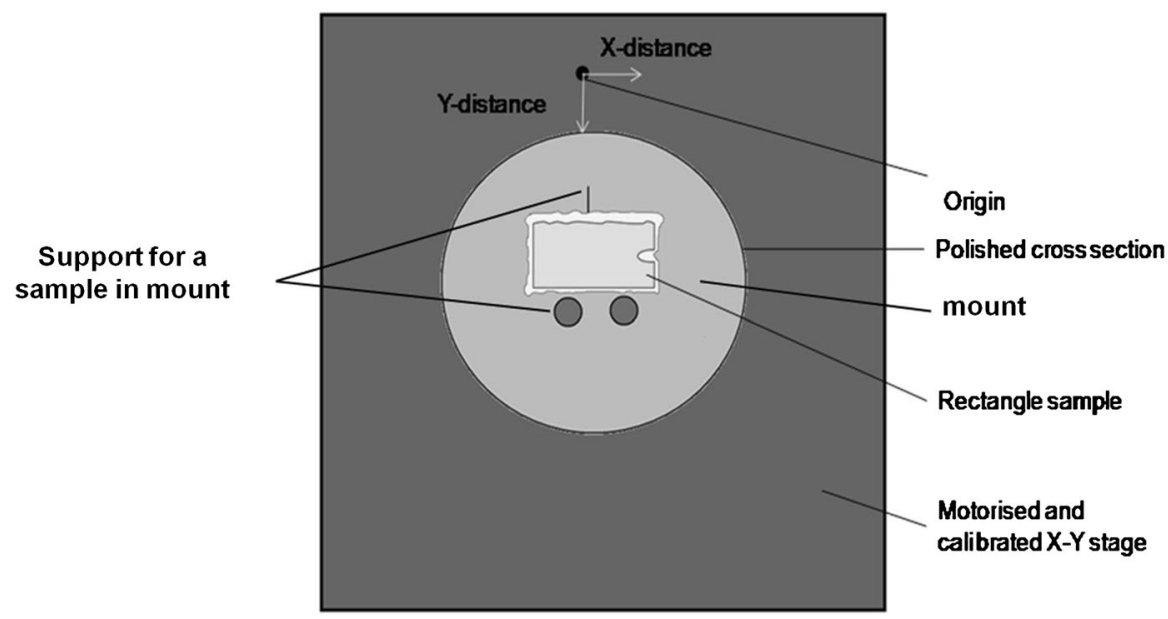

Fig. 3 Schematic of a rectangular samples cross-section on the digital image analyser stage 


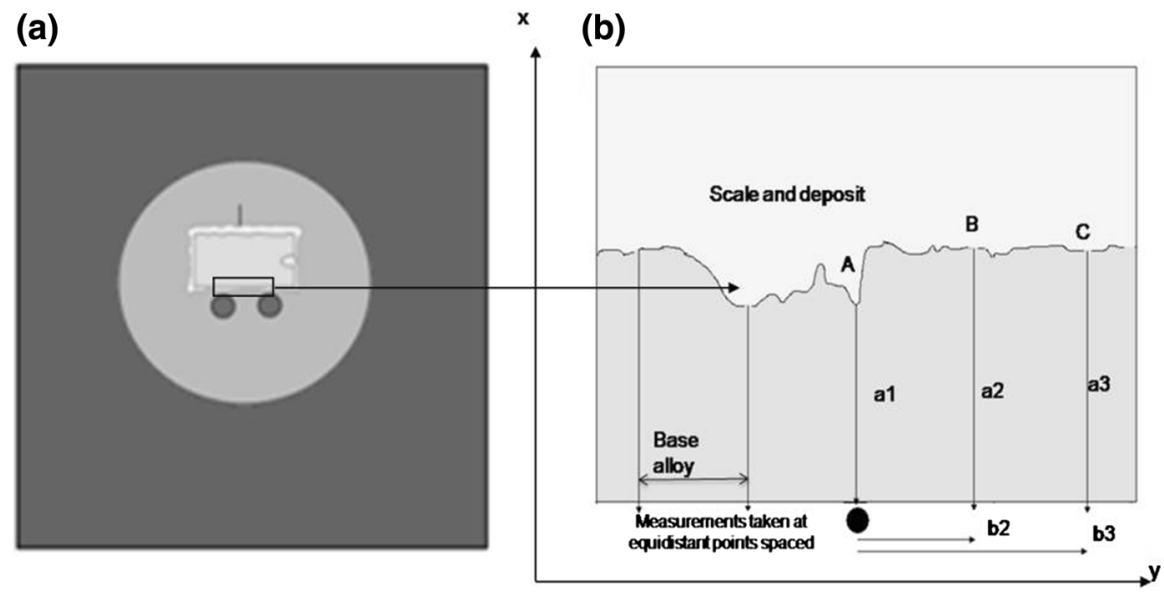

Fig. 4 Illustration of function of image analyser a stage and sample and $\mathbf{b}$ determining metal loss from the images recorded

thickness changes data were obtained from the specimens cross-sections with use of both SEM and optical microscopy after 250, 500 and $1000 \mathrm{~h}$ periods. Additionally the thickness change was calculated from the weight change data. For the calculation it was assumed that for $1 \mathrm{mg} / \mathrm{cm}^{2}$ of oxygen $7.094 \mu \mathrm{m}$ of magnetite or $4.078 \mu \mathrm{m}$ of chromia is able to form under tested conditions for ferritic and austenitic steels respectively.

Steam oxidation kinetics of ferritic steels was investigated in terms of mass, thickness and metal loss, whereas due to slow oxidation of the austenitic steels used in this work it was not possible to obtain thickness and metal loss data under tested

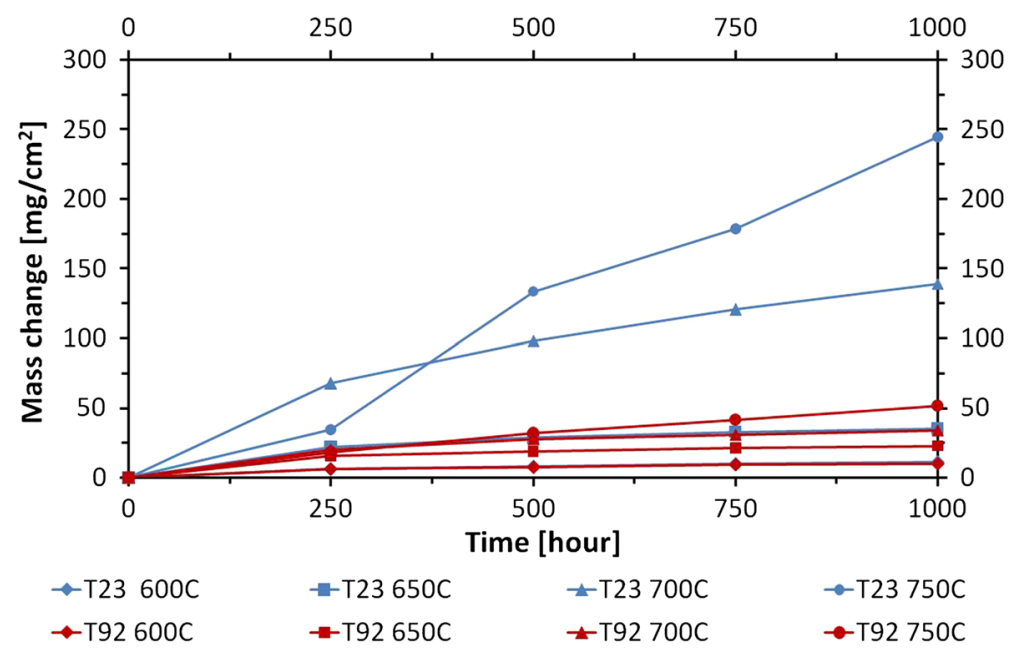

Fig. 5 Mass change of T23 and T92 steels in temperature range between 600 and $750{ }^{\circ} \mathrm{C}$ 
condition. The method used for the metal loss identification is characterised with an error of $6 \mu \mathrm{m}$ which has significant impact on accuracy of the data obtain for highly alloyed steels and Ni based steels, whereas for low alloyed steels such error is less significant for the results accuracy.

\section{Results}

Test conduced clearly show that steam oxidation kinetics of the selected ferritic and austenitic steels depends on temperature. For the ferritic and ferritic/martensitic steels (T23 and T92) oxidation process accelerates more significantly with temperature then for austenitic steels (Figs. 5, 6).

At $600{ }^{\circ} \mathrm{C}$ the oxidation process of both ferritic steels show similar rates, this changes with the exposure conditions. At 650,700 and $750{ }^{\circ} \mathrm{C}$ T23 steels indicates significantly faster oxidation, furthermore temperature has more significant impact on the process than it has for T92 steel. Oxidation of austenitic steels is much slower than that for ferritic steels; however, also shows clear temperature dependence. T347HFG and Super 304H austenitic grade steels clearly indicated change of the oxidation rates at elevated temperature under tested conditions. Even at the lowest temperature, there are differences in mass change between the two steels. Steam oxidation of T23 ferritic steel differs significantly from the rest of tested steels; first of all is much faster, secondly at higher temperatures $\left(700\right.$ and $\left.750{ }^{\circ} \mathrm{C}\right)$ it continuously accelerates with time, whereas for other materials it slows down after 250 and $500 \mathrm{~h}$ for $\mathrm{T} 92$ ferritic/martensitic and austenitic steels respectively. Oxidation process of T23 steel at 600 and $650{ }^{\circ} \mathrm{C}$ is characterised by fast period at the beginning of the process (first $250 \mathrm{~h}$ ) after which the kinetics slows down. Such situation was identified in all analysed data (mass, thickness and metal loss). At

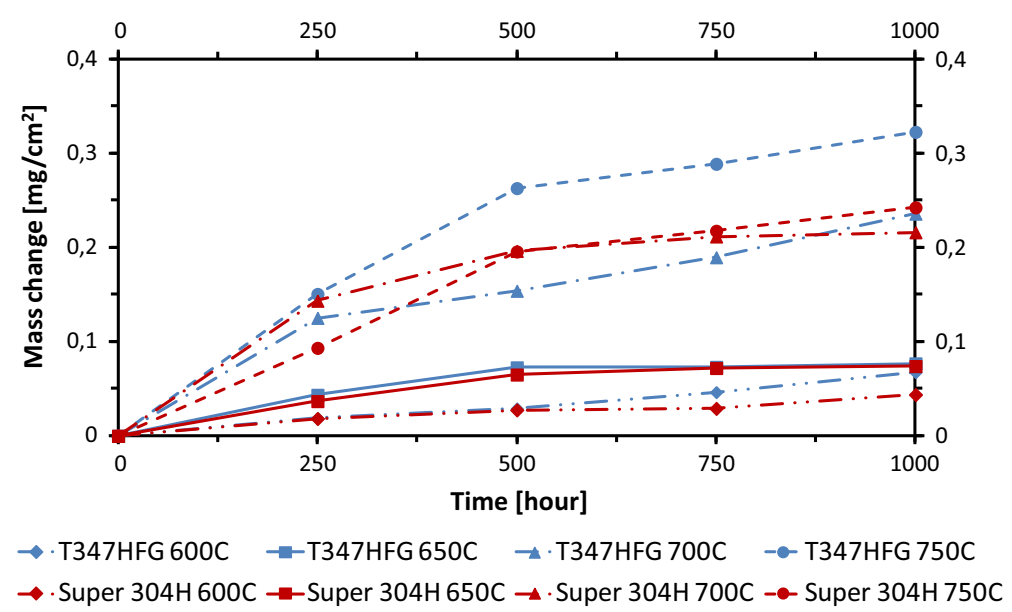

Fig. 6 Change of calculated oxide thickness of T23 and T92 steels with time in temperature range between 600 and $750{ }^{\circ} \mathrm{C}$ 
higher temperatures the oxidation rate increases continuously for the whole test duration. At $700{ }^{\circ} \mathrm{C}$ the fastest mass change was identified in the first $250 \mathrm{~h}$ period whereas at $750{ }^{\circ} \mathrm{C}$ the acceleration of oxidation rate in the first period is slower than after $250 \mathrm{~h}$.

Figure 7 shows comparison of steam oxidation of richer in Cr T92 steel with T23 steel in terms of average calculated oxide thickness. It was found that average calculated oxide thickness curve for T92 steel does not change significantly with temperature as it was in the case of T23 steel. Oxidation and calculated average oxide thickness of T92 steel at 650 and $700{ }^{\circ} \mathrm{C}$ shows similar values; the difference is in the first $250 \mathrm{~h}$ period when the rate growth is more significant at $700{ }^{\circ} \mathrm{C}$; however, it slows down with time. Under analysed conditions the T92 steel shows significantly faster growth at the beginning of the process, which reduces with exposure period, such situation, exists even at the highest temperatures. The phenomena is related to diffusion path, where with increasing time outward diffusion of ions from the bulk steel increases significantly, as well known this process is activated thermally such as at higher temperature the process will be more significant.

Figure 8 showing data of effect of $\mathrm{Cr}$ and average oxide thickness is calculated from mass change data, those values differ from the data obtain from the cross sectioned specimens in case of T23 steel at the higher temperatures (700 and $750{ }^{\circ} \mathrm{C}$ ), whereas at lower temperatures the calculated and obtain thickness data seem to be in better accordance. It was found that when mass change of T23 reached $250 \mathrm{mg} / \mathrm{cm}^{2}$ (Fig. 5) average thickness of the oxide scale showed value of $2500 \mu \mathrm{m}$ at $750{ }^{\circ} \mathrm{C}$, similar T92 mass change at $750{ }^{\circ} \mathrm{C}$ corresponded to nearly $50 \mathrm{mg} / \mathrm{cm}^{2}$ with average thickness of oxide equivalent to nearly $500 \mu \mathrm{m}$. It can be concluded, that in ferritic steel such as T23 and ferritic/martensitic steel T92 ratio 1:10 between mass change and average oxide thickness of the formed scale exists. Similar ratio

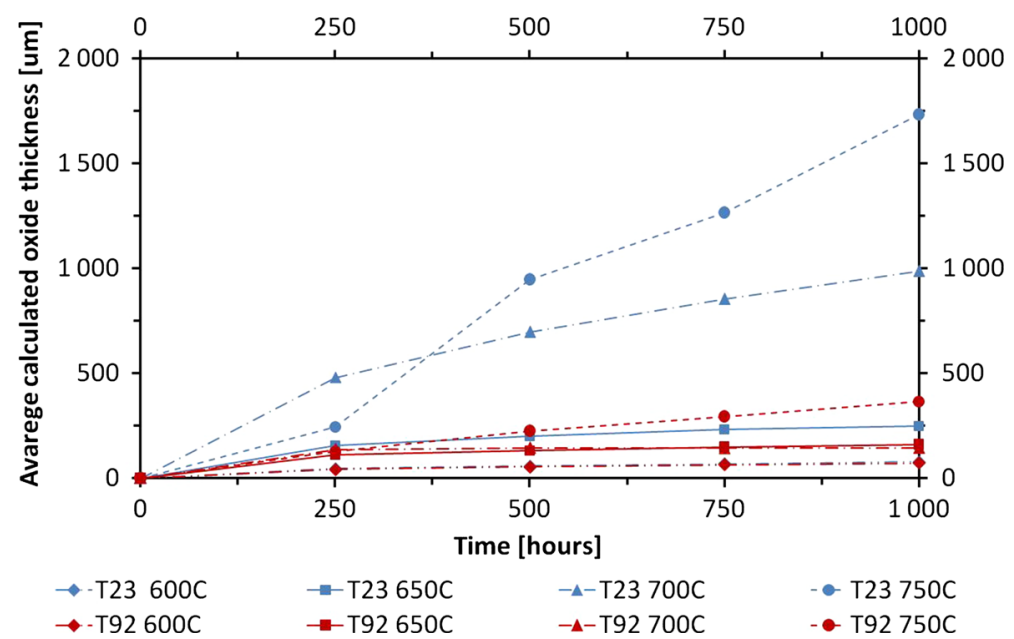

Fig. 7 Effect of chromium and average oxide thickness for T23 and T92 steels with time in temperature range between 600 and $750{ }^{\circ} \mathrm{C}$ 


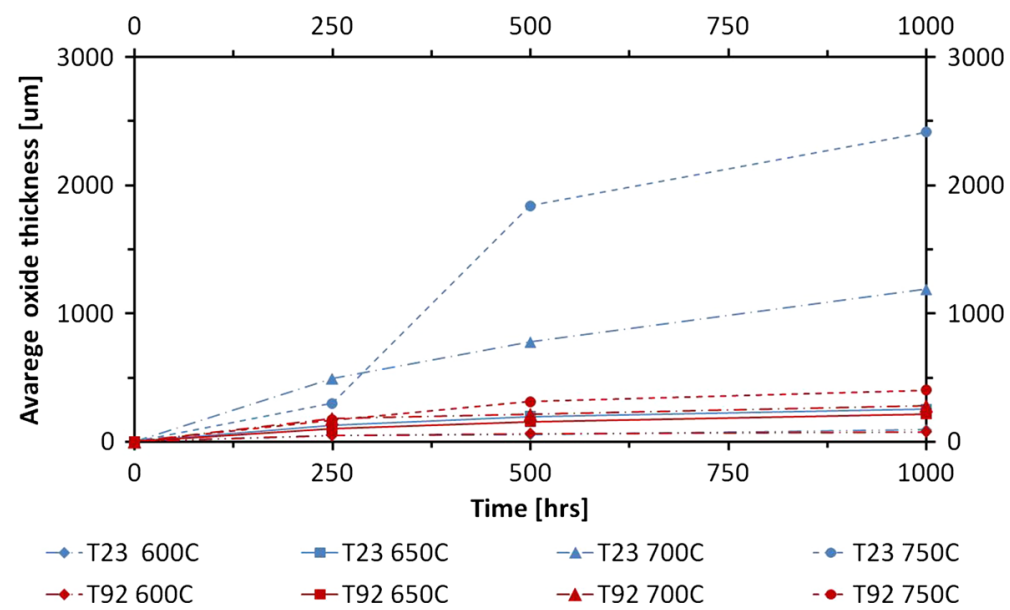

Fig. 8 Effect of chromium and average metal loss of T23 and T92 steels with time in temperature range between and $750{ }^{\circ} \mathrm{C}$

was observed as well for T23 steel at $700{ }^{\circ} \mathrm{C}$ where mass change of T23 material reached nearly $125 \mathrm{mg} / \mathrm{cm}^{2}$ (Fig. 5) while average oxide showed thickness of 1250 $\mu \mathrm{m}$.

Relation between oxide thickness and metal loss showing slightly different correspondence; is equivalent (in terms of ferritic steels) to an approximately $50 \%$ of total metal thickness. When average oxide thickness of T23 steel reaches 2500 $\mu \mathrm{m}$, metal loss of the steel reaches approximately $1200 \mu \mathrm{m}$ (Fig. 9).

Austenitic steels indicate significantly slower oxidation rates in steam regime at high temperature as assumed; the mass change of the selected steels increases clearly with temperature (Fig. 10). Under tested conditions T347HFG steel oxidises

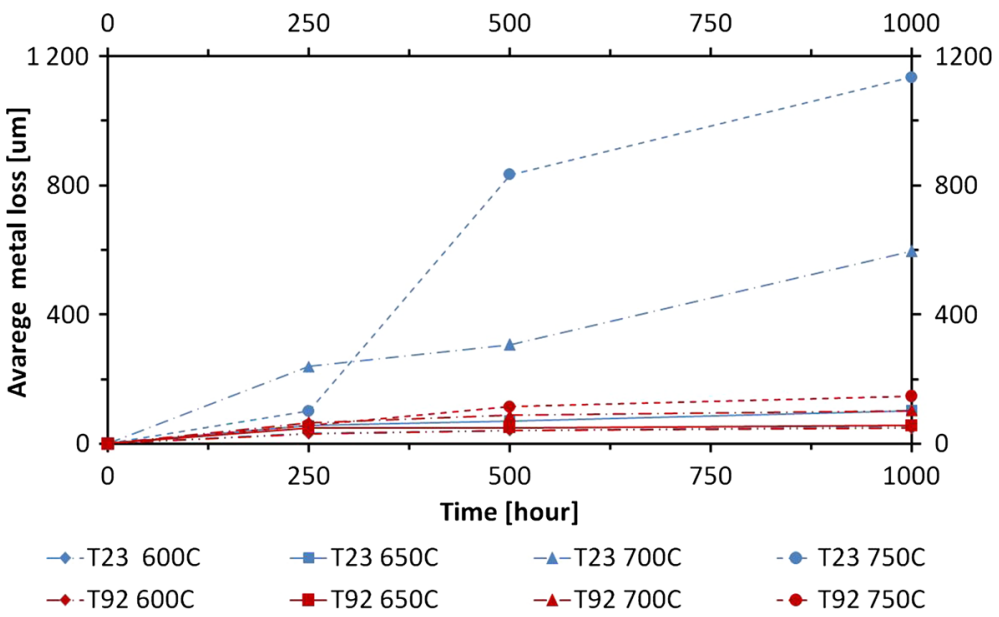

Fig. 9 Mass change of T347HFG and Super $304 \mathrm{H}$ steels in temperature range between 600 and $750{ }^{\circ} \mathrm{C}$ 


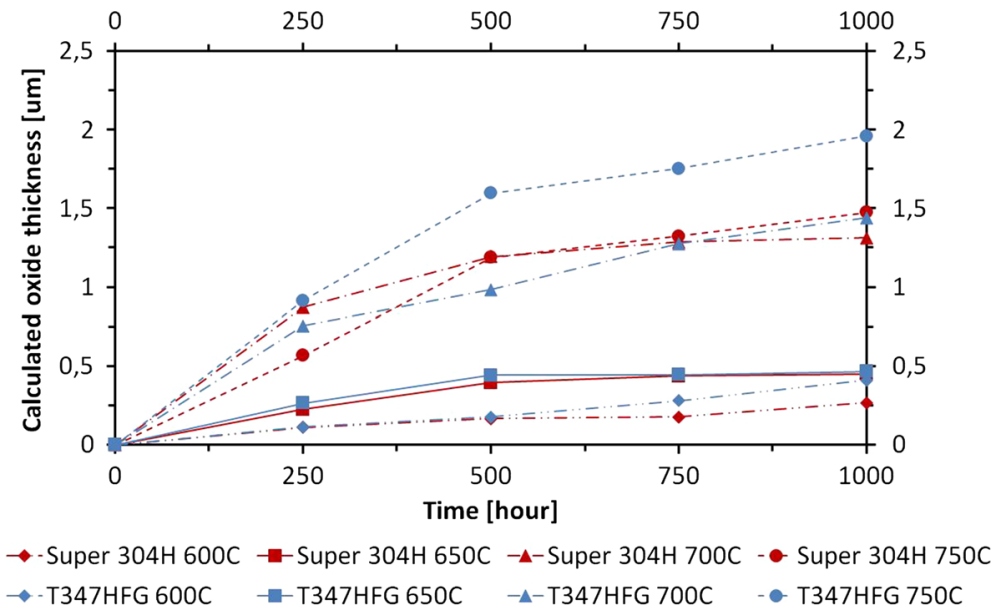

Fig. 10 Change of calculated thickness of T347HFG and Super 304H steels with time in temperature range between 600 and $750{ }^{\circ} \mathrm{C}$

slightly faster than Super $304 \mathrm{H}$ steel in terms of calculated oxide thickness, the smallest difference in the mass change between the analysed materials were identified at 600 and $650{ }^{\circ} \mathrm{C}$ respectively, however such similarity does not exists during whole exposure as it was identified in case of the ferritic materials. Steam oxidation of austenitic steels shows faster mass change at the beginning of the process up to first $500 \mathrm{~h}$, after this period the mass gain considerably slows down, such trend is identified at four studied temperatures for both selected austenitic steels with $18 \mathrm{wt} \% \mathrm{Cr}$. In contrast to ferritic steels, in austenitic steels ratio 1:10 between mass change and average oxide thickness of the formed scale doesn't exists suggesting completely different mechanism of oxide scale formation and corrosion behaviour at high temperature.

To summarise, the analysed materials have diverse oxidation rates, which differ with the chromium content as well as with alloying additions. Chromium content seems to have lower impact on the oxidation of T23 and T92 at $600{ }^{\circ} \mathrm{C}$ for whole test duration, the same trend was observed for austenitic steels moreover the positive impact of the alloying additions starts to be significant at higher

Table 2 Values of the parabolic rate constant $\left(\mathrm{k}_{\mathrm{p}}\right)\left(\mathrm{mg}^{2} / \mathrm{cm}^{4} / \mathrm{s}\right)$ for exposed steels at $600,650,700$ and $750{ }^{\circ} \mathrm{C}$

\begin{tabular}{lllll}
\hline Steel/temperature & $600{ }^{\circ} \mathrm{C}$ & $650{ }^{\circ} \mathrm{C}$ & $700{ }^{\circ} \mathrm{C}$ & $750{ }^{\circ} \mathrm{C}$ \\
\hline T23 & $3.01 \times 10^{-05}$ & $2.79 \times 10^{-04}$ & $5.47 \times 10^{-03}$ & $2.10 \times 10^{-02}$ \\
T92 & $2.50 \times 10^{-05}$ & $1.02 \times 10^{-04}$ & $2.74 \times 10^{-04}$ & $8.54 \times 10^{-04}$ \\
T347HFG & $1.55 \times 10^{-09}$ & $1.35 \times 10^{-09}$ & $2.93 \times 10^{-08}$ & $2.87 \times 10^{-08}$ \\
Super304H & $5.37 \times 10^{-10}$ & $1.48 \times 10^{-09}$ & $9.48 \times 10^{-09}$ & $1.77 \times 10^{-08}$ \\
\hline
\end{tabular}


temperatures and after longer exposure. Data analysis shows that oxidation rate of the studied materials in steam follows the parabolic dependence; therefore, the mass change may be fitted into the relation:

$$
\Delta \mathrm{m}=\mathrm{k}_{\mathrm{p}} \mathrm{t}^{2}+\mathrm{C}\left[\mathrm{mg} / \mathrm{cm}^{2}\right]
$$

where $\Delta \mathrm{m}$ is mass change, $\mathrm{k}_{\mathrm{p}}$ is parabolic rate constant, $\mathrm{t}$ is time and $\mathrm{C}$ is constant. Based on the Eq. (1) the $\mathrm{k}_{\mathrm{p}}$ for the analysed steels were calculated, the acquired values of parabolic rate constant are presented in Table 2.

The steam oxidation behaviour is assumed to follow the parabolic dependence; therefore, Arrhenius equation may describe the relationship between the parabolic rate and temperature:

$$
\mathrm{k}_{\mathrm{p}}=\mathrm{k}_{\mathrm{o}} \exp (-\mathrm{Q} / \mathrm{RT})\left[\mathrm{mg}^{2} / \mathrm{cm}^{4} / \mathrm{s}\right]
$$

where $\mathrm{Q}$ is activation energy, $\mathrm{R}$ is the gas constant and $\mathrm{T}$ is temperature. The logarithmic plot of the Eq. (2) allows calculating the activation energy by fitting the trend line to the points representing the $\mathrm{k}_{\mathrm{p}}$ for particular steel at the temperature of interest. The acquired values of activation energies calculations are presented in Table 3.

The results below show the values of the parabolic rate constant and activation energies derived from thickness and metal loss change data, only for T23 and T92 steels. The outcomes are shown in Tables 4 and 5 respectively. It was found that activation energies derived from those data are slightly larger than that obtain exclusively from the mass change only; however the differences are not very significant.

Steam oxidation of the selected materials leads to diverse metal loss, which is more severe at higher temperature, due to enhanced diffusion of the iron and therefore depletion of the base material. Investigation of the metal loss of the ferritic steels can be obtain in two ways: one by checking the thickness of the inner layer which corresponds to the original metal surface [16]; second by using the optical microscope connected to the computer with the appropriate software which allows taking pictures of the cross sectioned samples, allowing identification of the coordinates for each of the selected point on the interface between the metal and oxide scale. Further the data is transfer to excel and analysed statistically; the results of such study are presented in Fig. 11 for 600 and $650{ }^{\circ} \mathrm{C}$ exposures and Fig. 12 for 700 and $750{ }^{\circ} \mathrm{C}$ respectively.

Steam oxidation of the ferritic steels leads to large metal loss, which differs with steel type and exposure temperature. At lower temperatures $\left(600\right.$ and $650{ }^{\circ} \mathrm{C}-$

Table 3 Activation energy for the analysed ferritic and austenitic steels derived from mass change data

\begin{tabular}{ll}
\hline Steel type & Activation energy $(\mathrm{kJ} / \mathrm{mol})$ \\
\hline T23 & -337 \\
T92 & -172 \\
T347HFG & -163 \\
Super304H & -183 \\
\hline
\end{tabular}


Table 4 Values of the parabolic rate constant $\left(\mathrm{k}_{\mathrm{p}}\right)\left(\mu \mathrm{m}^{2} / \mathrm{s}\right)$ for analysed steels at 600, 650, 700 and $750{ }^{\circ} \mathrm{C}$ based on thickness of the oxide scale

\begin{tabular}{llllll}
\hline $\begin{array}{l}\text { Steel/ } \\
\text { temperature }\end{array}$ & $600{ }^{\circ} \mathrm{C}$ & $650{ }^{\circ} \mathrm{C}$ & $700{ }^{\circ} \mathrm{C}$ & $750{ }^{\circ} \mathrm{C}$ & $\begin{array}{l}\text { Activation energy } \\
(\mathrm{kJ} / \mathrm{mol})\end{array}$ \\
\hline $\mathrm{T} 23$ & $2.47 \times 10^{-03}$ & $1.73 \times 10^{-02}$ & $4.37 \times 10^{-01}$ & $2.02 \times 10^{-02}$ & -346 \\
$\mathrm{~T} 92$ & $1.10 \times 10^{-03}$ & $1.34 \times 10^{-02}$ & $1.74 \times 10^{-02}$ & $4.75 \times 10^{-02}$ & -173 \\
\hline
\end{tabular}

Table 5 Values of the parabolic rate constant $\left(\mathrm{k}_{\mathrm{p}}\right)\left(\mu \mathrm{m}^{2} / \mathrm{s}\right)$ for analysed steels at $600,650,700$ and $750{ }^{\circ} \mathrm{C}$ derived from metal loss data

\begin{tabular}{llllll}
\hline $\begin{array}{l}\text { Steel/ } \\
\text { temperature }\end{array}$ & $600{ }^{\circ} \mathrm{C}$ & $650{ }^{\circ} \mathrm{C}$ & $700{ }^{\circ} \mathrm{C}$ & $750{ }^{\circ} \mathrm{C}$ & $\begin{array}{l}\text { Activation energy } \\
(\mathrm{kJ} / \mathrm{mol})\end{array}$ \\
\hline $\mathrm{T} 23$ & $6.36 \times 10^{-04}$ & $2.81 \times 10^{-03}$ & $1.16 \times 10^{-01}$ & $4.54 \times 10^{-01}$ & -347 \\
$\mathrm{~T} 92$ & $4.76 \times 10^{-04}$ & $2.84 \times 10^{-04}$ & $2.25 \times 10^{-03}$ & $6.63 \times 10^{-03}$ & -145 \\
\hline
\end{tabular}

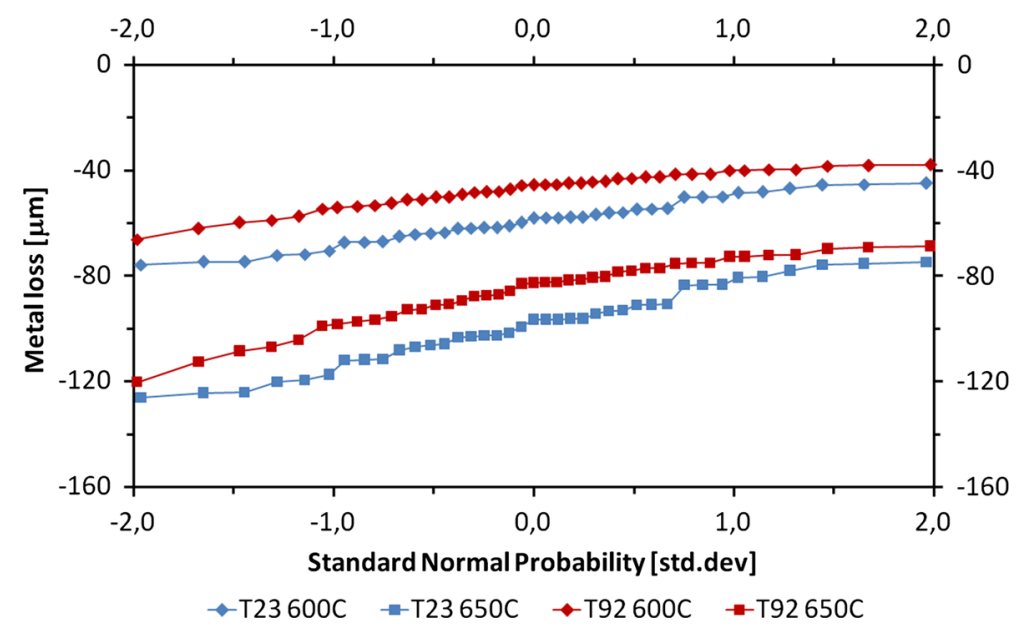

Fig. 11 Metal loss data of the analysed T23 and T92 after $1000 \mathrm{~h}$ exposure at 600 and $650{ }^{\circ} \mathrm{C}$

Fig. 11) the differences in metal loss between T23 and T92 steels equal around $25 \%$, it changes at higher temperatures $\left(700\right.$ and $750{ }^{\circ} \mathrm{C}-$ Fig. 12) when T23 steel indicates more severe material loss, the difference in that case is up to $600 \%$.

Comparison of the metal loss and oxide thickness shows that for ferritic steels the material consumed equals around half of the thickness of the oxides scales formed (Fig. 13). The metal loss/oxide thickness ratio varies with temperature and steel type, for T23 the ratio is $0.64,0.34,0.46$, and 0.50 for $600,650,700$ and $750{ }^{\circ} \mathrm{C}$ 


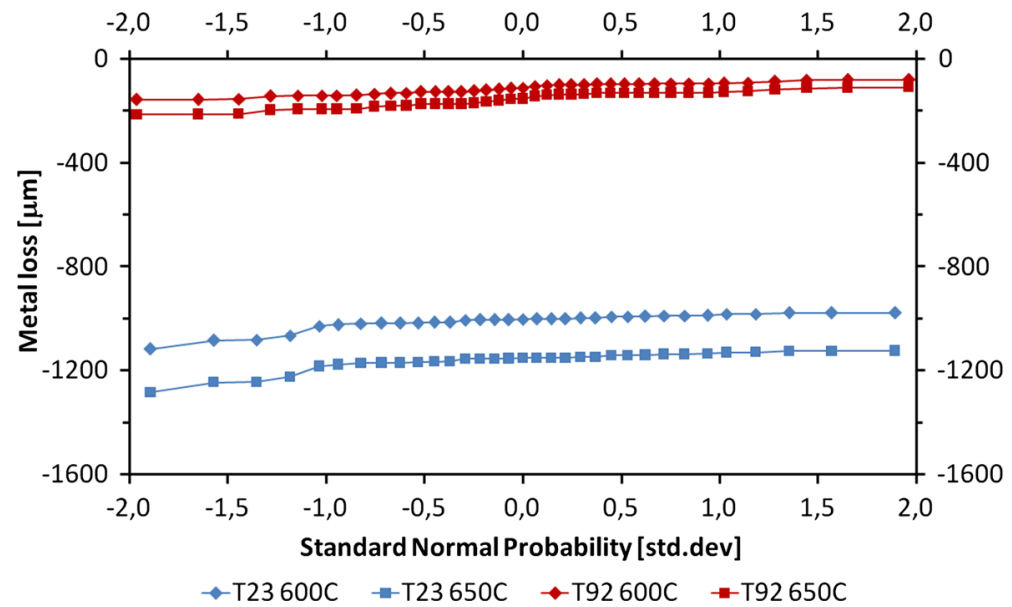

Fig. 12 Metal loss of the analysed T23 and T92 after $1000 \mathrm{~h}$ exposure at 700 and $750{ }^{\circ} \mathrm{C}$

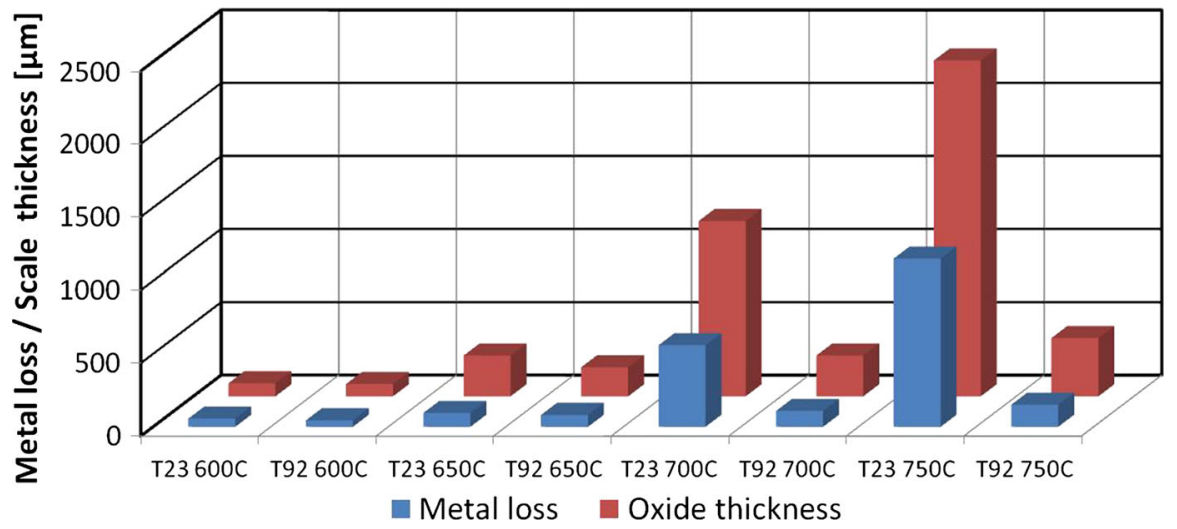

Fig. 13 Comparison between the oxide scale thickness and metal loss of T23 and T92 at $600-750{ }^{\circ} \mathrm{C}$ after $1000 \mathrm{~h}$ exposure in steam

respectively, whereas for $\mathrm{T} 92$ is $0.52,0.41,0.40$ and 0.38 , the lower values of the ratio for $\mathrm{T} 92$ are result of the scale spallation.

\section{Discussion}

When ferritic steels are exposed to the $100 \%$ steam environment the oxidation rate is initially low as the most stable oxides are formed, which in case of considered steels are chromia, $\mathrm{Fe}-\mathrm{Cr}$ spinel and $\mathrm{Fe}_{2} \mathrm{O}_{3}$. The length of the initial oxidation period differs with the chromium content, the alloying additions [1] and the exposure temperature [16]. During that stage the process follows the linear 
dependence which is in agreement with Natesan and Park [25]. After longer time when the protective scale brakes down and the growth of magnetite is possible the rate dependence changes to parabolic; the oxidation rate remains parabolic as long as the developed scale is able to maintain adherence [26]. Nevertheless, the change between the oxidation rates is well documented; there is no agreement when it happens, the transformation point depends on many variables [27] therefore is complicated to be identified. In case of the tests conducted, it varies with temperature, what is result of changes in diffusion at different temperatures and therefore faster breakaway oxidation of the protective oxides formed on the surface of the bare steel [1, 28]. Viswanatahen and Sarver [27] believe that oxidation of the ferritic steels exhibits linear rate dependence above $700{ }^{\circ} \mathrm{C}$; however results of the particular test show that at $700{ }^{\circ} \mathrm{C}$ the oxidation of $\mathrm{T} 92$ steel still follows more closely the parabolic rate dependence. In comparison the oxidation of T23 for the whole duration at 700 and $750{ }^{\circ} \mathrm{C}$ sharply accelerates therefore conclusion that for that steel the rate dependence may closely follow linear law after longer exposure. Analysis of the activation energy for ferritic steels were based on three types of data, activation energy values obtain form those data are characterised with some dispersion. It is explained due to problems of determination of the precise area exposed to direct oxidation due to the diverse surface shape of the specimen (concave, convex and flat surfaces), as well as the exfoliation of scale during weighting. Based on those explanation the values obtain form the thickness measurement are consider to be more precise and are in better accordance with data found in the literature [10]. Wright and Dooley [18] show that activation energy for steam oxidation of T23 and T92 in the temperature range between 550 and $700{ }^{\circ} \mathrm{C}$ equals -368 and $-197 \mathrm{~kJ} / \mathrm{mol}$ respectively. The difference between the results obtained from tests conducted and literature review is most probably results of different testing practice [4]. Interpretation of the activation energy shows that the process controlling steam oxidation of ferritic steels is mix of inward oxygen and outward metal cations diffusion mostly iron, which is in accordance with theories presented in the literature [29]. However according to Viswanatahen and Sarver [27] there is no clear interpretation of the rate controlling mechanism due to fact that values of the activation energy top of the range reported for $\mathrm{Fe}$ diffusion in $\mathrm{FeO}$ and bottom of $\mathrm{Fe}$ diffusion in $\mathrm{Fe}_{3} \mathrm{O}_{4}$.

Steam oxidation is clearly temperature dependent; the rate accelerates with temperature, it is explained due to faster diffusion of cations at higher temperature due to their atomic movements [1]. Oxidation kinetics of the T23 and T92 steels oxidation in temperature range between 650 and $750{ }^{\circ} \mathrm{C}$ varies significantly, whereas at $600{ }^{\circ} \mathrm{C}$ there difference between the oxidation rate of T23 and T92 is smaller. Such situation could be explained due to lower impact of the chromium content on the oxidation of ferritic steels at lower temperatures. The reduced impact of $\mathrm{Cr}$ is a result of slower diffusion of metal ions at $600{ }^{\circ} \mathrm{C}$ as the diffusion coefficients are temperature dependent [29, 30]. It could be also explained as a result that neither of those two steels has sufficient amount of chromium which can effectively suppress the non-protective oxide growth at higher temperatures [31].

Nevertheless there is no agreement on the impact of chromium at different temperatures, it is well recognised that steels with higher chromium level exhibits 
better oxidation resistance due to formation of more protective oxides, however again there is no clear evidence of the minimum $\mathrm{Cr}$ content which is sufficient for development of the protective chromium oxides. Shibli and Starr [32] indicated that $10-11 \%$ of chromium in material allows the protective, external chromia $\left(\mathrm{Cr}_{2} \mathrm{O}_{3}\right)$ to be formed; on the other hand Sanchez et al. [31] have shown that such level suppose to be around 11-12\%.

Metal loss of the tested ferritic steels increases with exposure temperature and decreasing chromium content [33]. Under tested conditions the T23 exhibits larger metal loss than T92 that is associated with higher chromium content of T92. In theory between the metal loss/oxide scale thickness ratio equals around 1:2 [18]; however for tests conducted it fluctuates with the exposure conditions, such situation is explained due to the scale exfoliation. At $600{ }^{\circ} \mathrm{C}$, however there is no significant differences in the metal loss between these two materials which is explained as a result of relatively slower diffusion [30] and lower impact of the chromium content on oxidation under considered conditions [27, 33].

The exposure of the austenitic steels under $100 \%$ steam conditions leads to significantly slower mass change than for ferritic steels, the linear growth of the scale is longer due to higher chromium level, after longer exposure T347HFG and Super304H exhibits parabolic rate dependence [18, 34]. The transformation between the rates depends on the exposure temperature; it is faster under higher conditions. Analysis of the activation energy shows that the protective scale growth is not controlled by inner diffusion of oxygen as it could be expected but due to internal oxidation of the $\mathrm{Cr}$ [17]. The tests conducted reveal good steam oxidation resistance of the studied austenitic steels due to higher chromium content. Nonetheless the both steels are $18 \mathrm{Cr}$ with fine grain structure their oxidation behaviour differs, this is associated with higher Ni content of Super304H [35] and positive impact of the nitrogen within the base material [36]. The activation energies for the two steels are in accordance with data in literature, Fry et al. [35] show that for T347HFG the activation energy is $-164 \mathrm{~kJ} / \mathrm{mol}$, the data for Super 304 was not available however for the 300 series family the activation energy is accounted for $-200 \mathrm{~kJ} / \mathrm{mol}$.

\section{Conclusions}

Study conducted reveal significant differences in oxidation behaviour among tested T23, T92, T347HFG and Super304H. Those in the first place are explained due to different properties of the ferritic and austenitic steel, secondly due to the chromium and alloying addictions.

Ferritic steels show fast oxidation under studied conditions which is result of the enhanced diffusion of the metal ions, there are not efficient diffusion barriers to reduce the ionic transport and therefore suppress development of the non-protective scale. Oxidation of both ferritic steels is fast and it increases with exposure temperature. Results shows that chromium level has impact on slowing down the oxidation process in steam however the $9 \% \mathrm{Cr}$ in $\mathrm{T} 92$ is not enough to slow down 
oxidation rates so that steel can be employed in power plant operating at tested temperatures.

Austenitic steels on the other hand oxidise in significantly slower manner as result of the protective oxides development. Such layers are able to successfully suppress formation of un-protective iron oxides for analysed period, therefore the tested materials exhibit low oxidation rates. Tests have shown that T347HFG is less resistant to steam than Super304H; which is explained due to a positive impact of nickel and nitrogen addictions and synergy of those elements with other alloying addictions.

To summarise data generated shows that applications of ferritic steels due to fast metal loss are significantly limited, whereas austenitic steels should find wider applications at studied temperatures, however their performance should be a subject of the further longer steam oxidation tests.

Acknowledgments We would like to acknowledge the support of The Energy Programme, which is a Research Councils UK cross council initiative led by EPSRC and contributed to by ESRC, NERC, BBSRC and STFC, and specifically the Supergen initiative (Grants GRyS86334y01 and EPyF029748) and the following companies; Alstom Power Ltd., Doosan Babcock, E.ON, National Physical Laboratory, Praxair Surface Technologies Ltd, QinetiQ, Rolls-Royce plc, RWE npower, Siemens Industrial Turbomachinery Ltd. and Tata Steel, for their valuable contributions to the project.

Open Access This article is distributed under the terms of the Creative Commons Attribution 4.0 International License (http://creativecommons.org/licenses/by/4.0/), which permits unrestricted use, distribution, and reproduction in any medium, provided you give appropriate credit to the original author(s) and the source, provide a link to the Creative Commons license, and indicate if changes were made.

\section{References}

1. P. J. Ennis and W. J. Quadakkers, International Journal of Pressure Vessels and Piping 84, 75 (2007).

2. N. Komai, F. Masuyama and M. Igarashi, Journal of Pressure Vessel Technology 127, 190 (2005).

3. J. Gabrel, C. Coussement, L. Verelst, R. Blum, Q. Chen and C. Testani, Materials Science Forum 369-372, 931 (2001).

4. W. Quadakkers, P. Ennis, J. Zurek and M. Michalik, Materials At High Temperatures 22, 27 (2005).

5. I. Wright, A. Sabau and R. Dooley, Materials Science Forum 595-598, 387 (2008).

6. M. Igarashi, Creep Properties of Heat Resistant Steels and Superalloys, 1st ed, (Springer, Berlin, 2003).

7. F. Abe, T.-M. Kern and R. Viswanathan, Creep-Resistant Steels, 1st ed, (Woodhead Publishing, Cambridge, 2008).

8. I. G. Wright, P. J. Maziasz, F. V. Ellis, T. B. Gibbons, and D. A. Woodford, in 29th International Technical Conference on Coal Utilization and Fuel Systems (2004).

9. S. R. J. Saunders and L. N. McCartney, Materials Science Forum 522-523, 119 (2006).

10. R. Viswanathan and W.T. Bakker, in 2000 International Joint Power Conference (ASME, Miami Beach, 2000), pp. 2-22.

11. J. Ehlers, D. J. Young, E. J. Smaardijk, A. K. Tyagi, H. J. Penkalla, L. Singheiser and W. J. Quadakkers, Corrosion Science 48, 3428 (2006).

12. D. Laverde, T. Gomez-Acebo and F. Castro, Corrosion Science 46, 613 (2004).

13. E. Essuman, G. H. Meier, J. Zurek, M. Hansel and W. J. Quadakkers, Oxidation of Metals 69, 143 (2008). 
14. P. J. Maziasz, I. G. Wright, J. P. Shingeldecker, T. B. Gibbons, and R. R. Romanosky, in 4th International Conference on Advance Materials Technology for fossil Power Plants (2005), pp. 602-620.

15. M. Schutze, M. Schorr, D. Renusch, A. Donchew and J. Vossen, Material Research 7, 111 (2004).

16. A. Hansson, K. Pantleon, F. Grumsen and M. Somers, Oxidation of Metals 73, 289 (2009).

17. A. N. Hansson and M. Montgomery, Materials Science Forum 522-523, 181 (2006).

18. I. G. Wright and R. B. Dooley, International Materials Reviews 55, 129 (2010).

19. Draft Code of Practice for Discontinuous Corrosion Testing in High Temperature Gaseous Atmospheres. EC project SMT4-CT95-2001, TESTCORR. ERA Technology, Surrey (2000).

20. Corrosion of Metals and Alloy-Method for Metallographic Examination of Samples after Exposure to High Temperature Corrosive Environments. Draft ISO standard. ISO/TC 156 NWI 5092005 (2006).

21. S. R. J. Saunders, in Guidelines for Methods of Testing and Research in High Temperature Corrosion, eds. H. J. Grabke and D. B. Meadowcroft (The Institute of Metals, London, 1995).

22. N. J. Simms and A. T. Fry, in Proceedings of Materials for Advanced Power Engineering, eds. J. Lecomte-Beckers and M. Carton (Forschungszentrum Julich GmbH, 2010).

23. T. Hussain, T. Dudziak, N. J. Simms and J. R. Nicholls, Journal of Thermal Spray Technology 22, 797 (2013).

24. T. Dudziak, S. Grobauer, N. Simms, U. Krupp and M. Łukaszewicz, High Temperature Materials and Processes 2015. doi:10.1515/htmp-2014-0164.

25. K. Natesan and J. H. Park, International Journal of Hydrogen Energy 32, 36890 (2007).

26. J. Zurek, E. Wessel, L. Niewolak, F. Schmitz, T. U. Kern, L. Singheiser and W. J. Quadakkers, Corrosion Science 46, 2301 (2004).

27. R. Viswanathan, J. Sarver and J. M. Tanzosh, Journal of Materials Engineering and Performance 15, 255 (2005).

28. D. Young, High Temperature Oxidation and Corrosion of Metals, Effect of Water Vapour on Oxidation, (Elsevier, Amsterdam, 2008).

29. A. Khanna, Introduction to High Temperature Oxidation and Corrosion, (ASM International, New York, 2002).

30. M. Glicksman, Diffusion in Solids Field theory, Solid-State Principles and Applications, (Wiley, Toronto, 2000).

31. L. Sanchez, M. P. Hierro and F. J. Perez, Oxidation of Metals 71, 173 (2009).

32. A. Shibili and F. Starr, Pressure Vessels and Piping 84, 114 (2007).

33. V. Lepingle, G. Louis, D. Petelot, B. Lefebvre and J. Vaillant, Materials Science Forum 369-372, 239 (2001).

34. Program on Technology Innovation: Oxide Growth and Exfoliation on Alloys Exposed to Steam (Electric Power Research Institute, California 2007).

35. A. Fry, S. Osgerby and M. Wright, Oxidation of Alloys in Steam-A review, (National Physical Laboratory, Tedington, 2002).

36. A. Iseda, H. Okada, H. Semba and M. Igarashi, Long Term Creep Properties and Microstructure of Super 304H, T347HFG and HR3C for Advanced USC Boilers, (ASM International, Materials Park, 2008). 